\title{
Synthesis of Poly(3-Hydroxybutyrate)/Copper Sulfide Composites Films and their Photocatalytic Application
}

\author{
Nur Irmakeytie Ismail, Mohamad Abu Bakar* and Noor Hana Hanif Abu Bakar \\ School of Chemical Sciences, Universiti Sains Malaysia, \\ 11800 USM Pulau Pinang, Malaysia \\ *Corresponding author: bmohamad@usm.my
}

Published online: 25 February 2018

To cite this article: Ismail, N. I, Abu Bakar, M. \& Abu Bakar, N. H. H. (2018). Synthesis of poly(3-hydroxybutyrate)/copper sulfide composites films and their photocatalytic application. J. Phys. Sci., 29(Supp. 1), 115-123, https://doi.org/10.21315/jps2018.29.s1.15

To link to this article: https://doi.org/10.21315/jps2018.29.s1.15

\begin{abstract}
The objectives of this study were to synthesise and characterise poly(3hydroxybutyrate)/copper sulfide (PHB/CuS) composites and to assess the potential of these composites in the form of films as photocatalyst for the degradation of 2,4,6trichlorophenol (TCP). The CuS was prepared by the reaction between copper(II) chloride dihydrate and thiourea which was later immobilised onto PHB biopolymer by aqueous to organic phase transfer method, i.e., hydrosol to organosol. Based on UV-Vis and Raman spectroscopy as well as XRD analysis, it was confirmed that the hydrosol contain mostly $\mathrm{CuS}$ with the existence of $\mathrm{Cu}_{2} \mathrm{~S}$ in trace amount. This trace amount of $\mathrm{Cu} \mathrm{u}_{2} \mathrm{~S}$ can be minimised by prolonged refluxing of the reaction mixture. The amount of $\mathrm{Cu}$ in the composite film was determined using AAS technique. Pristine PHB and the synthesised photocatalysts containing various amount of $\mathrm{CuS}$ were investigated for photodegradation of TCP using $U V$-visible light (350-800 nm). Pristine PHB was capable to degrade TCP to a maximum of $70 \%$ degradation at $5 \mathrm{~h}$. However, the PHB/CuS composite film afforded higher TCP degradation in shorter time. The photodegradation results also revealed that the higher amount of $\mathrm{CuS}$ in the composite led to better photodegradation of TCP under UV-visible light. In this study, complete degradation of TCP was achieved after 2 h of irradiation upon utilisation of $\mathrm{PHB} / \mathrm{CuS}$ film containing $0.312 \mathrm{wt} \%$ of $\mathrm{CuS}$.
\end{abstract}

Keywords: Poly(3-hydroxybutyrate), photocatalytic degradation, 2,4,6-trichlorophenol, $\mathrm{PHB} / \mathrm{CuS}$ nanocomposites film 


\section{INTRODUCTION}

Chlorophenols (CPs) are common environmental pollutants. ${ }^{1}$ They have been classified as priority pollutants by the U.S. Environmental Protection Agency (EPA) due to their high toxicity, carcinogenic properties and bioaccumulation capability. ${ }^{2}$ The CPs include 2-chlorophenol, 2,4-dichlorophenol, 2,4,6-trichlorophenol (TCP) and phencyclidine. Among these CPs, TCP is found to be the most abundant and mostly originates from textile and pesticide industries. ${ }^{1} \mathrm{TCP}$ is reported to affect the human nervous, respiratory and cardiovascular systems and is also carcinogenic. ${ }^{1}$ Therefore, removal of TCP from wastewater is crucial because of its high stability, toxicity, and persistence in the environment.

Copper sulfide (CuS) has nowadays been attracting studies due to their interesting optical and electrical properties. CuS exists in various stoichiometry and morphologies. There are five types of stoichiometry at room temperature such as covellite (CuS), anilite $\left(\mathrm{Cu}_{1.75} \mathrm{~S}\right)$, digenite $\left(\mathrm{Cu}_{1.8} \mathrm{~S}\right)$, djurlite $\left(\mathrm{Cu}_{1.95} \mathrm{~S}\right)$ and chalcocite $\left(\mathrm{Cu}_{2} \mathrm{~S}\right) .{ }^{3} \mathrm{CuS}$ is applicable in catalysis reaction.

Poly(3-hydroxybutyrate)(PHB) is the most common polymer among the polyhydroxyalkanoates (PHAs). It is obtainable from various microorganisms. PHB has thermoplastic properties and is non-toxic as well as $100 \%$ biodegradable. $^{4}$ PHB based composites have attracted much interest and they have been applied in many field of researches, i.e., thermal, mechanical and photocatalytic degradation of organic dyes. PHB incorporated with $\mathrm{TiO}_{2}$ or niobium oxyhydroxide has previously been applied in the photodegradation of methylene blue. ${ }^{5-8}$ However, there is no study on using PHB/CuS composites for the photodegradation of TCP.

Herewith, we report preliminary development of a new catalytic system based on the PHB polymer films containing copper sulfide. The catalyst hydrosol was synthesised via reflux method and the polymer composite organosol was synthesised using phase transfer method. The PHB/CuS composite films were obtained upon drying the later. The photocatalytic removal of TCP was then investigated using UV-vis light irradiation in the wavelength region of $350-800 \mathrm{~nm}$.

\section{EXPERIMENTAL}

\subsection{Materials}

Poly(3-hydroxybutyrate), PHB was supplied by Biocycle, Brazil. Cetyltrimethylammonium bromide, CTAB (Merck, Germany), chloroform, methanol and isopropanol (Qrec, Malaysia), potassium hydroxide pellets, $\mathrm{KOH}$ 
(Qrec, Malaysia), thiourea (Riedel-de Haen, Germany), copper(II) chloride dihydrate (Sigma-Aldrich, USA), were obtained commercially and used without further purification.

\subsection{Preparation of $\mathrm{PHB} / \mathrm{CuS}$ and Photodegradation of TCP}

The $\mathrm{PHB} / \mathrm{CuS}$ composite films were obtained via two-step aqueous to organic phase transfer method where the $\mathrm{CuS}$ particles were first formed in the aqueous phase (hydrosol) then followed by the transfer of the CuS particles in the hydrosol into an organic phase comprising PHB in chloroform (organosol). Isopropanol was used as the inter-phase transfer agent for the CuS particles.

In a typical preparation, two sets of aqueous solutions were prepared which are $0.04 \mathrm{~g} \mathrm{CTAB}$ and $0.02 \mathrm{~g} \mathrm{CuCl}_{2} \cdot 2 \mathrm{H}_{2} \mathrm{O}$ and others consisting of $0.02 \mathrm{~g}$ thiourea and $0.02 \mathrm{~g} \mathrm{KOH}$. Both solution was stirred separately for $30 \mathrm{~min}$ before mixing. The total volume of the resultant mixture is $200 \mathrm{ml}$. The resultant mixture was then refluxed at $120^{\circ} \mathrm{C}$ for $3 \mathrm{~h}$ to obtain the hydrosol. Upon cooling the CuS hydrosol, a solution of PHB in chloroform and isopropanol was added under vigorous stirring for $1 \mathrm{~h}$. The mixture was allowed to stand to facilitate the separation of the aqueous and organic phase. The former was then removed. The remaining organic phase (organosol) was cast into a beaker and was left to dry in the fume hood at room temperature for $24 \mathrm{~h}$ to yield $\mathrm{PHB} / \mathrm{CuS}$ composite film. Films of the various PHB/ $\mathrm{CuS}$ composites were prepared in a similar manner by varying the amount of $\mathrm{CuS}$ as listed in Table 1.

The photodegradation of TCP was carried out by introducing $20 \mathrm{ml}$ of $100 \mathrm{ppm}$ TCP aqueous solution into a beaker containing $\mathrm{PHB} / \mathrm{CuS}$ composite film. This was then irradiated with Xe lamp (UV-vis light with wavelength 350-800 nm) with continuous stirring. The degraded TCP solution was then analysed using UV-vis spectroscopy technique.

Table 1: Condition for the fabrication of $\mathrm{PHB} / \mathrm{CuS}$ film.

\begin{tabular}{lcccccc}
\hline CuS Hydrosol (ml) & 2 & 6 & 10 & 20 & 30 & 40 \\
PHB stock solution (ml) & 5 & 5 & 5 & 5 & 5 & 5 \\
Isopropanol (transfer agent) (ml) & 2 & 4 & 6 & 9 & 12 & 15 \\
$\mathrm{Cu}$ in PHB/CuS nanocomposite films (wt\%) & 0.013 & 0.017 & 0.044 & 0.130 & 0.263 & 0.312 \\
\hline
\end{tabular}

* as determined by $A A S$ 


\subsection{Characterisation}

The optical properties of the hydrosol, organosol, and TCP were determined using a Hitachi U-2000 UV-Vis spectrophotometer. The Raman spectroscopy of $\mathrm{CuS}$ particles was determined using a Jobin Yvon Horiba HR800 UV. The X-ray diffraction (XRD) patterns were obtained using SIEMENS D5000 X-ray diffractometer. The CuS particle samples were collected via centrifugation of the hydrosol whereas $\mathrm{PHB} / \mathrm{CuS}$ film samples were obtained by evaporating the chloroform from the organosol. The metal content in the sample (expressed in $\mathrm{wt} \%$ of $\mathrm{CuS}$ ) was determined using Perkin Elmer Analyst 100 atomic absorption spectrometer (AAS).

\section{RESULTS AND DISCUSSION}

\subsection{Preparation of CuS Hydrosol}

From Figure 1, the UV-Vis spectroscopy indicates that in the first $15 \mathrm{~min}$, the formation of $\mathrm{CuS}$ does not occur initially as there is no absorption peak observed at around $800-1100 \mathrm{~nm}$. This thus explained the brownish colour that is observed in first $15 \mathrm{~min}$ of refluxing is due to $\mathrm{Cu}_{2} \mathrm{~S}$ only. The $\mathrm{CuS}$ formed only after prolong refluxing. There also occur the shift from a higher wavelength to a lower wavelength then up to higher wavelength again. According to Zhang et al., the shift from higher wavelength to lower wavelength infers the formation of smaller particles while lower to higher wavelength indicates the formation of larger particles. $^{9}$

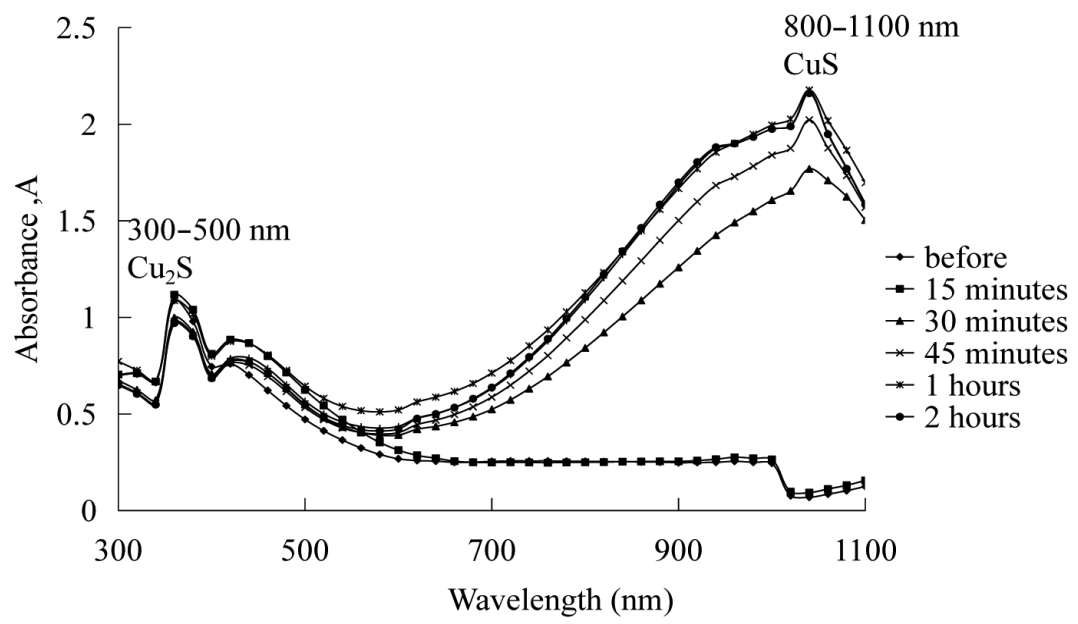

Figure 1: UV-vis spectroscopy for CuS nanoparticles. 
The possible mechanism of the formation $\mathrm{CuS}$ and $\mathrm{Cu}_{2} \mathrm{~S}$ particles is shown in Equations 1 to 4. Equation 1 shows the hydrolysis of thiourea. Thiourea generates the sulfide $\left(\mathrm{S}^{2-}\right)$ ion. Copper(II) ion can easily be reduced to copper(I) ion by thiourea as shown in Equation 2. The $\mathrm{S}^{2-}$ ion consequently reacted with $\mathrm{Cu}^{+}$ions to form $\mathrm{Cu}_{2} \mathrm{~S}$ (Equation 3) and with $\mathrm{Cu}^{2+}$ ion to form $\mathrm{CuS}$ (Equation 4). The CTAB stabilised the formed particles. ${ }^{10}$

$$
\begin{aligned}
& \mathrm{NH}_{2} \mathrm{CSNH}_{2}+2 \mathrm{OH}^{-} \longrightarrow \mathrm{S}^{2-}+\mathrm{NH}_{2} \mathrm{CONH}_{2}+\mathrm{H}_{2} \mathrm{O} \\
& 2 \mathrm{Cu}^{2+}+2\left(\mathrm{NH}_{2}\right)_{2} \mathrm{CS} \longleftrightarrow 2 \mathrm{Cu}^{2+}+\left(\mathrm{NH}_{2}\right) \mathrm{C}_{2} \mathrm{~S}_{2}+2 \mathrm{H}^{+} \\
& 2 \mathrm{Cu}^{+}+\mathrm{S}^{2-} \longrightarrow \mathrm{Cu}_{2} \mathrm{~S} \\
& \mathrm{Cu}^{2+}+\mathrm{S}^{2-} \longrightarrow \mathrm{CuS}
\end{aligned}
$$

$\mathrm{CuS}$ is inactive in the infrared region. Figure 2 shows the Raman spectrum of a typical sample. There is a sharp peak observed at $459 \mathrm{~cm}^{-1}$ along with the smaller peak at $236 \mathrm{~cm}^{-1}$. These peaks observed were attributed to the said copper sulfide. ${ }^{11}$

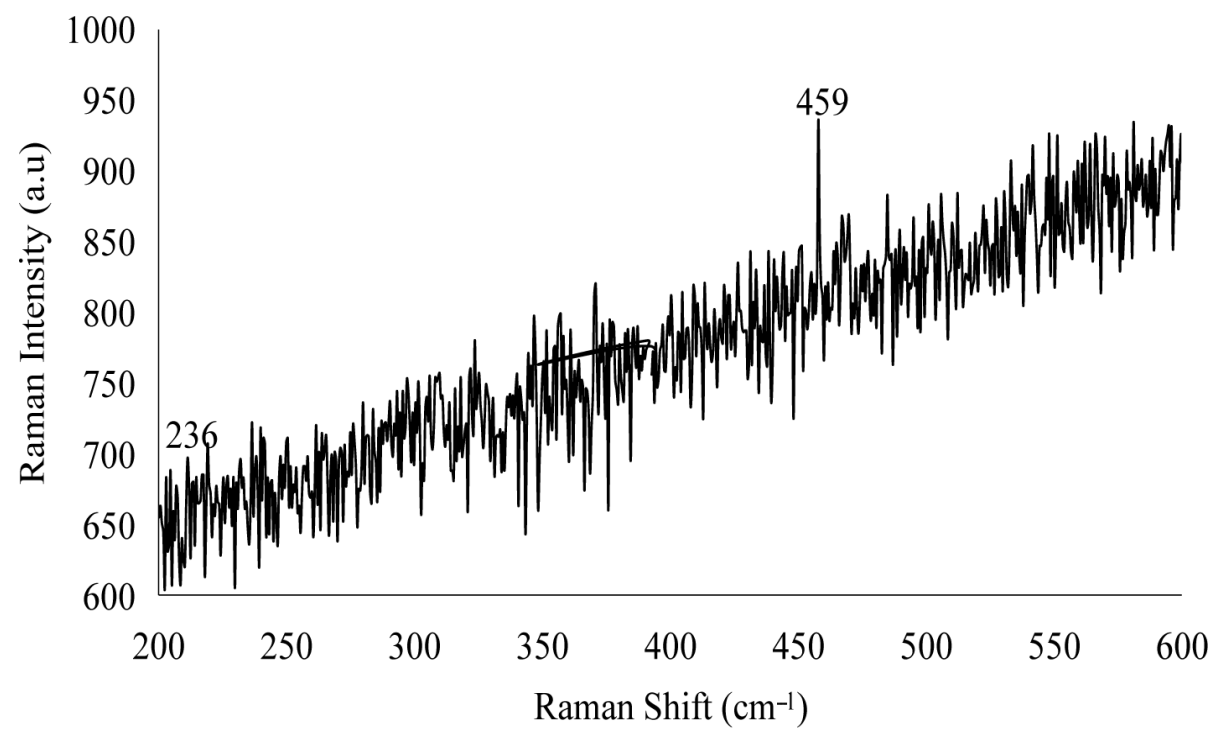

Figure 2: Raman spectrum of CuS nanoparticles.

Typical XRD patterns of the CuS particles is shown in Figure 3(a). ${ }^{12}$ According to the literature, the $\mathrm{CuS}$ sample is closely related to the covellite phase and $\mathrm{Cu}_{2} \mathrm{~S}$ are close to the chalcocite phase. ${ }^{11}$ Therefore, based on UV-vis and Raman spectroscopy as well a XRD analysis, it is confirmed that the hydrosol contain mostly $\mathrm{CuS}$ with the existence of $\mathrm{Cu}_{2} \mathrm{~S}$ in trace amount. 

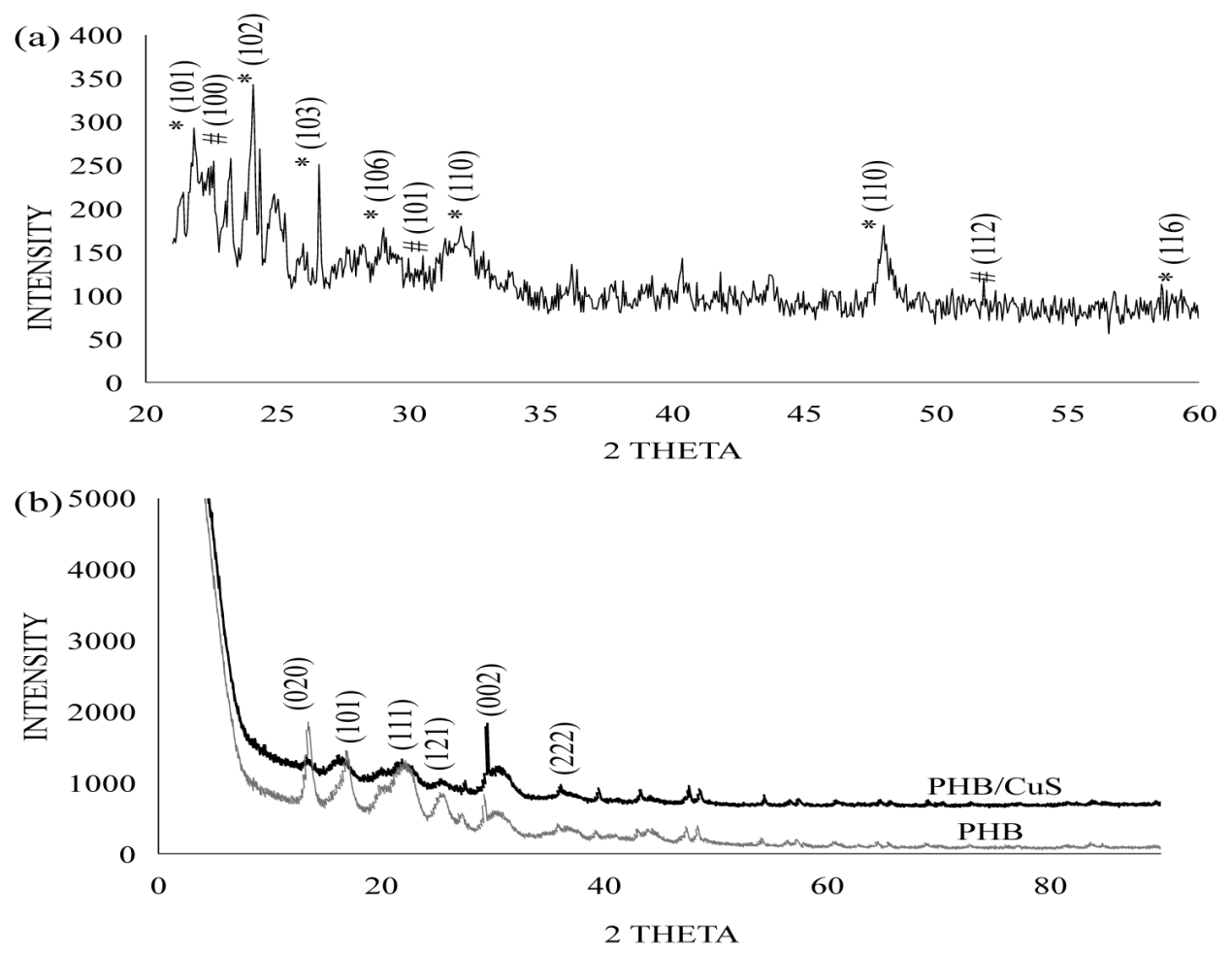

Figure 3: $\mathrm{XRD}$ diffractogram of (a) $\mathrm{CuS}$ nanoparticles [ ${ }^{*}$ is due to $\mathrm{CuS}$ and \# is due to $\mathrm{Cu}_{2} \mathrm{~S}$; (b) purified PHB and PHB/CuS composites film.

\subsection{Characterisation of the PHB/CuS Organosol/Composite Films}

The typical XRD pattern of the respective pure PHB and PHB/CuS composite films are shown in Figure 3(b). The PHB which has an orthorhombic unit cell with the crystal planes of (020), (101), (111), (121), (002) and (222) with the corresponding angles at $13.6^{\circ}, 17^{\circ}, 22.6^{\circ}, 26^{\circ}, 31.7^{\circ}$ and $44.5^{\circ}$ respectively. ${ }^{13} \mathrm{As}$ for $\mathrm{PHB} / \mathrm{CuS}$ nanocomposite, the peak observed for PHB become less intense due to the presence of $\mathrm{CuS}$ peaks as previously described. AAS analysis was carried out for all the $\mathrm{PHB} / \mathrm{CuS}$ composites films to determine the weight percentage (wt $\%$ ) of copper sulfide that have been transferred into the PHB. The results are as shown in Table 1.

\subsection{Photocatalytic Test}

As shown in Figure 4, when pristine PHB was employed, only a low percentage TCP removal was observed. On the other hand, $\mathrm{PHB} / \mathrm{CuS}$ composites showed better degradation of TCP than the pristine PHB. Without CuS catalyst, approximately 
$70 \%$ removal of TCP occurred after $5 \mathrm{~h}$. In the presence of catalysts, however, the degradation of TCP was completed after $2 \mathrm{~h}$ for the composite film containing $0.312 \mathrm{wt} \%$ of $\mathrm{CuS}$. This means that the $\mathrm{CuS}$ speeds up the removal of TCP. The removal of TCP increases with the increase in the $\mathrm{CuS}$ content in the composite film. The reason is as follows: upon $\mathrm{UV}$-vis irradiation of the $\mathrm{CuS}$, electron from the valence band (VB) excites to the conduction band (CB) leaving a hole in the $\mathrm{VB}$ (Equation 5). This hole reacts with $\mathrm{H}_{2} \mathrm{O}$ to produce hydroxyl radical (Equation 6) while the electron reacts with $\mathrm{O}_{2}$ to form superoxide radical anion (Equation 7). These radicals then attack the TCP forming $\mathrm{CO}_{2}$ and $\mathrm{H}_{2} \mathrm{O} .{ }^{14}$ Therefore, increasing the amount of $\mathrm{CuS}$ in $\mathrm{PHB} / \mathrm{CuS}$ film led to more production of radicals and consequently enhanced photodegradation of TCP as compared to pristine PHB.

$$
\begin{aligned}
& \mathrm{CuS}+\mathrm{hv} \longrightarrow \mathrm{h}^{+}{ }_{\mathrm{VB}}+\mathrm{e}_{\mathrm{CB}}^{-} \\
& \mathrm{H}_{2} \mathrm{O}+\mathrm{h}^{+}{ }_{\mathrm{VB}} \longrightarrow \mathrm{OH} \bullet+\mathrm{H}^{+} \\
& \mathrm{O}_{2}+\mathrm{e}_{\mathrm{CB}}^{-} \longrightarrow \mathrm{O}_{2} \bullet
\end{aligned}
$$

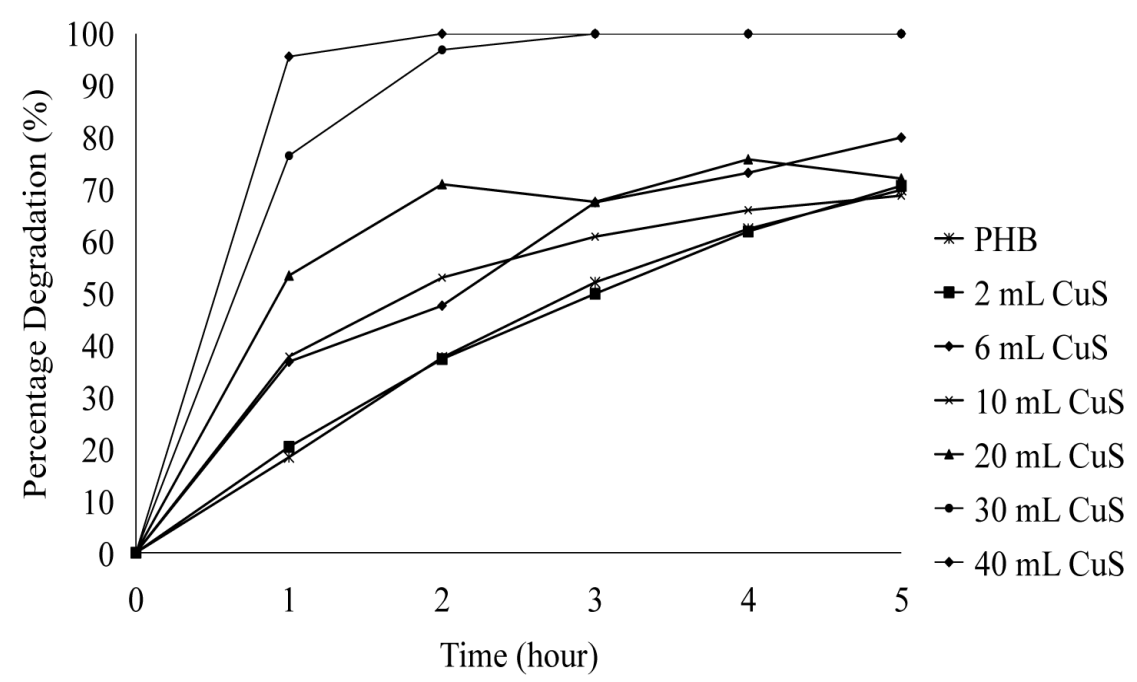

Figure 4: A profile of the percentage removal of TCP by PHB and PHB/CuS film over time in the presence of UV radiation (200-400 nm).

\section{CONCLUSION}

In this work, PHB incorporated with $\mathrm{CuS}$ catalyst was designed for the first time. The presence of $\mathrm{CuS}$ in the composites were evaluated using UV-vis spectroscopy and XRD techniques and the amount of $\mathrm{CuS}$ in the composites film 
were determined using AAS technique. The formed composites proved to be highly efficient photocatalyst for the removal of TCP in solution. The advantage of incorporating photocatalyst in polymer was that they do not need separation process after photocatalytic treatment. Furthermore, PHB was biodegradable and eco-friendly that make these resultant composite films invitingly biodegradable. Therefore, development of these composites film might be a novel method to remove chlorophenols in the environment. Further work is ongoing.

\section{ACKNOWLEDGEMENTS}

This work was supported by RU grants 1001/PKIMIA/811311 from Universiti Sains Malaysia (USM).

\section{REFERENCES}

1. Zango, Z. U. et al. (2016). Adsorption studies of $\mathrm{Cu}^{2+}-\mathrm{Hal}$ nanocomposites for the removal of 2,4,6-trichlorophenol. Appl. Clay Sci., 132-133(1), 6878, https://doi.org/10.1016/j.clay.2016.05.016.

2. Jin, M., Chen, X. \& Pan, B. (2006). Simultaneous determination of 19 chlorophenols in water by liquid chromatography-mass spectrometry with solid-phase extraction. J. Liq. Chromatogr. Relat. Technol., 29(9), 13691380, http://dx.doi.org/10.1080/10826070600598944.

3. Zhang, D. F. et al. (2011). Stoichiometry-controlled fabrication of $\mathrm{Cu}_{\mathrm{x}} \mathrm{S}$ hollow structures with $\mathrm{Cu}_{2} \mathrm{O}$ as sacrificial templates. Cryst. Growth Des., 11(9), 3748-3753, https://doi.org/10.1021/cg101283w.

4. Sudesh, K., Abe, H. \& Doi, Y. (2000). Synthesis, structure and properties of polyhydroxyalkanoates: Biological polyesters. Prog. Polym. Sci., 25(10), 1503-1555, https://doi.org/10.1016/S0079-6700(00)00035-6.

5. Yeo, S. Y. et al. (2010). Silver sulfide/poly(3-hydroxybutyrate) nanocomposites: Thermal stability and kinetic analysis of thermal degradation. Polym. Degrad. Stab., 95, 1299-1304, https://doi.org/10.1016/ j.polymdegradstab.2010.02.025.

6. Díez-Pascual, A. M. \& Díez-Vicente, A. L. (2014). Poly(3-hydroxybutyrate)/ ZnO bionanocomposites with improved mechanical, barrier, and antibacterial properties. Int. J. Mol. Sci., 15, 10950-10973, https://doi.org/10.3390/ ijms 150610950 .

7. Yew, S., Tang, H. \& Sudesh, K. (2006). Photocatalytic activity and biodegradation of polyhydroxybutyrate films containing titanium dioxide. Polym. Degrad. Stab., 91, 1800-1807, https://doi.org/10.1016/j. polymdegradstab.2005.11.011. 
8. Heitmann, A. P. et. al (2016). Nanostructured niobium oxyhydroxide dispersed poly (3-hydroxybutyrate) (PHB) films: Highly efficient photocatalysts for degradation methylene blue dye. Appl. Catal. B Environ., 189, 141-150, https://doi.org/10.1016/j.apcatb.2016.02.031.

9. Zhang, P. \& Gao, L. (2003). Copper sulfide flakes and nanodisks. J. Mater. Chem., 10, 2007-2010, https://doi.org/10.1039/B305584A.

10. Boey, H. T. et al. (2007). Formation and morphology of colloidal chitosanstabilized copper sulphides. J. Phys. Sci.,18(1), 87-101.

11. Munce, C. G. et al. (2007). A Raman spectroelectrochemical investigation of chemical bath deposited CuxS thin films and their modification. Coll. Surf. A Physicochem. Eng. Asp., 295, 152-158, https://doi.org/10.1016/j. colsurfa.2006.08.045

12. Cavalcante, M. P. et al. (2017). Correlation between traditional techniques and TD-NMR to determine the morphology of PHB/PCL blends. Polym. Test., 58, 159-165, https://doi.org/10.1016/j.polymertesting.2016.11.036

13. Zhijiang, C. et al. (2016). Poly(hydroxybutyrate)/cellulose acetate blend nanofiber scaffolds: Preparation, characterization, and cytocompatibility. Mater. Sci. Eng. C, 58, 757-767, https://doi.org/10.1016/j.msec.2015.09.048.

14. Saranya, M. et al. (2015). Enhanced visible light photocatalytic reduction of organic pollutant and electrochemical properties of CuS catalyst. Powder Technol., 279, 209-220, https://doi.org/10.1016/j.powtec.2015.03.041. 